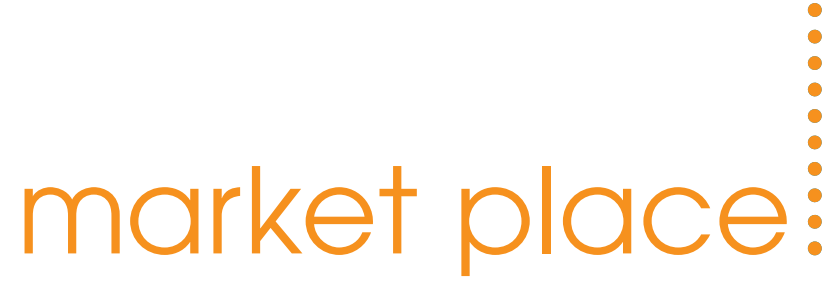

\section{New alcohol free mouthrinse}

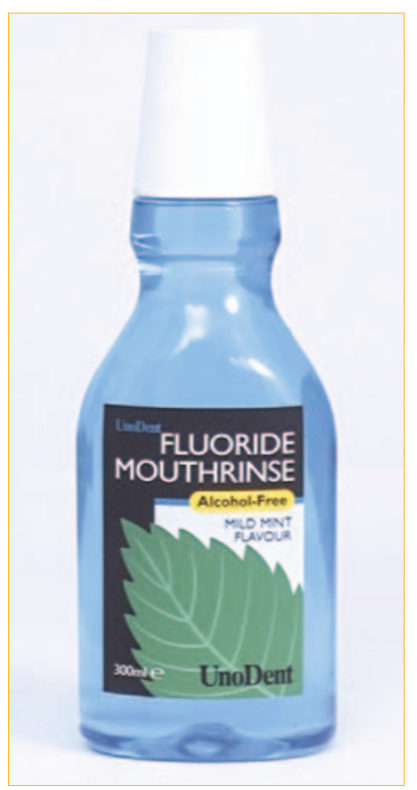

Teetotal patients may like the new alcohol-free mouthrinse from UnoDent. It contains $0.5 \%$ sodium fluoride to help strengthen tooth enamel and protect against cavities while cetylpyridinium chloride inhibits plaque build-up and freshens the breath. Each $300 \mathrm{ml}$ bottle has a tamperproof seal and a measuring cap. For a limited period it is available at a special introductory price of $£ 6$ for a case of six bottles. For further information contact The Dental Directory (www. dental-directory.co.uk).

\title{
Taking care of children's teeth
}

The British Dental Health Foundation has launched a "My Teeth" leaflet, to teach children about the importance of good oral health. This message can be difficult to pass on when a child is in the dentist's chair. But this colourful leaflet explains to children what their teeth are for, how to clean them and what foods will keep their mouths healthy. The leaflet also provides information on plaque and tooth decay and has a quiz. The brochure is the latest addition to the Foundation's popular Tell Me About series. The leaflets cost $£ 9.38$ for a pack of 100 for members and $\mathfrak{E} 12.50$ for non-members excluding VAT and P\&P. For further information contact 08707704015 .

\section{An aid to healing}

Gengigel professional fluid can be used to treat inflammatory conditions such as gingivitis, gingival bleeding and gingival retraction. The key ingredient of Gengigel is hyaluronan, which when applied to surgically traumatised gingival and periodontal tissue inhibits inflammation and accelerates tissue repair. Gengigel ( $0.1 \%$ hyaluronan $)$ comes in $500 \mathrm{ml}$ pump dispensers and is intended for in-prac-

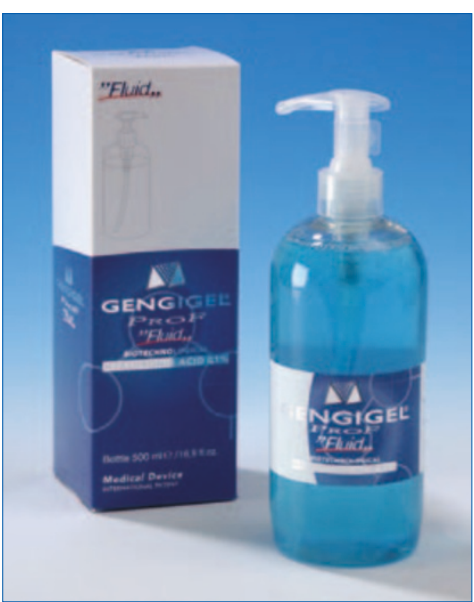
tice use where rapid healing is required after surgical intervention, implants, tooth extractions and root scaling. Gengigel also boasts haemostatic properties and the company claims it is able to stop gums bleeding within ten minutes of application. For further information call Oraldent on 01480862080.

\section{Additive free alternative}

\section{toothpaste}

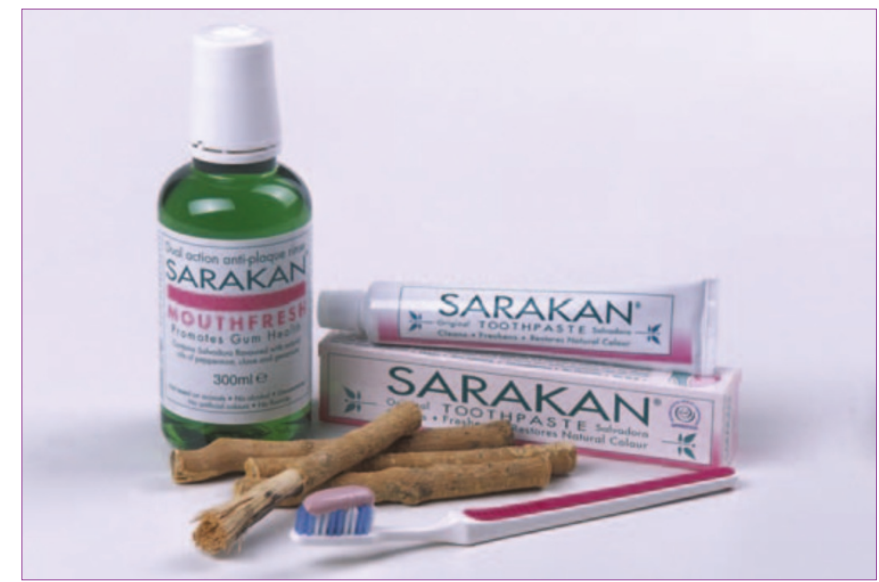

Patients looking for a herbal toothpaste might be interested in Sarakan which contains extract of a salvadora bush and is lightly flavoured with peppermint oil, clove and geranium. It contains no alcohol, sugar, artificial colours, sodium lauryl sulphate, or fluoride and is suitable for adults, children and vegans. The toothpaste has its origins in the Middle East where twigs from the salvadora persica shrub (the toothbrush tree) are chewed or beaten with a stone to form a fibrous brush which is then used to clean teeth and massage the gums. Sarakan was recently accredited by The British Dental Health Foundation and is available from health food stores and selected pharmacies. 


\section{market place}

\section{Surgery makeover \\ Looking to trans- form your waiting area? Admor's \\ Mobile dental treatment unit} range of furniture offers a wide variety of designs to create a welcoming and stylish reception area. Choose from straight or curved reception desks or modular units, all built to a high quality and offered in finishes and patterns to suit all tastes. Admor can also help enhance your reception area with dental-themed

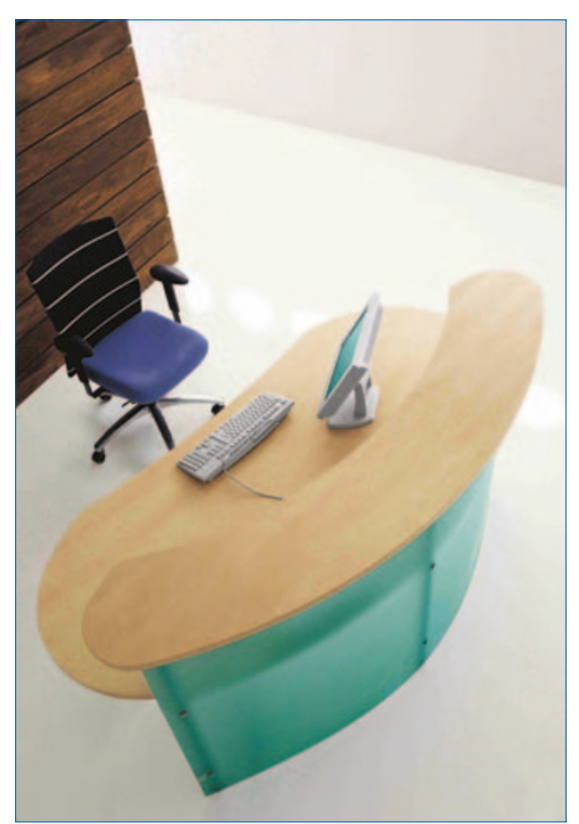

accessories to brighten up even the dullest rooms. Signage, coat hooks, tooth-shaped lamps doubling as stools, wall clocks, clip boards, hand mirrors, desk tidies, pen holders and much more will ensure patients arrive to a warm welcome and leave with smiles on their faces. For further information visit www.admor.co.uk

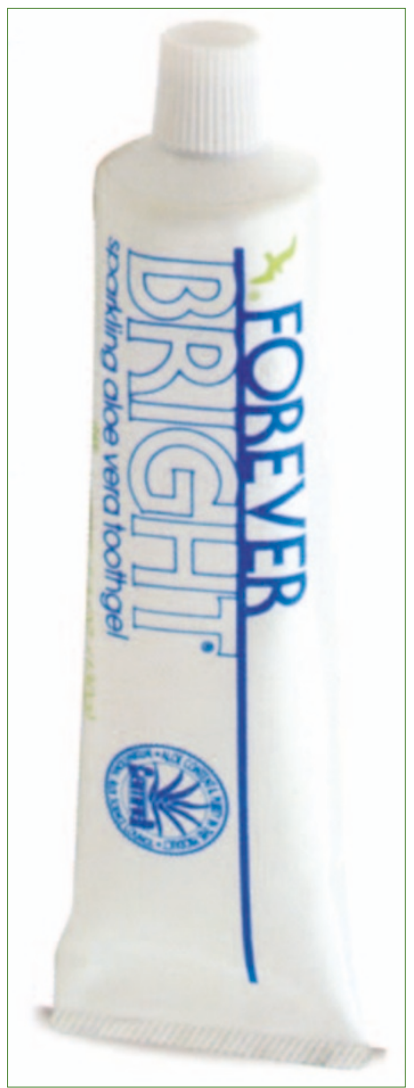

\section{Toothgel with} non-abrasive

\section{formula}

Forever Bright toothgel from Forever Living is based on the aloe vera plant with added bee propolis. The patented stabilisation process preserves the plant's anti-bacterial, antifungal, virucidal and healing properties. It fights plaque while improving the health of the gums and lining of the mouth. The non-abrasive formula has no fluoride or animal byproducts and is suitable for vegetarians. It also features an effective desensitising action and is a natural tooth whitener. a stabilised extract from
The Lysta PortaDent is a mobile hygienist and dental treatment unit, which can be carried in a laptop case. The PortaDent is available in three different models and makes dental treatment accessible to patients anywhere in the world. The quick to assemble device has been designed for use in various environments and hygiene is a key feature. All its surfaces are smooth, easy to clean and disinfect. PortaDent includes an oil free compressor, key-

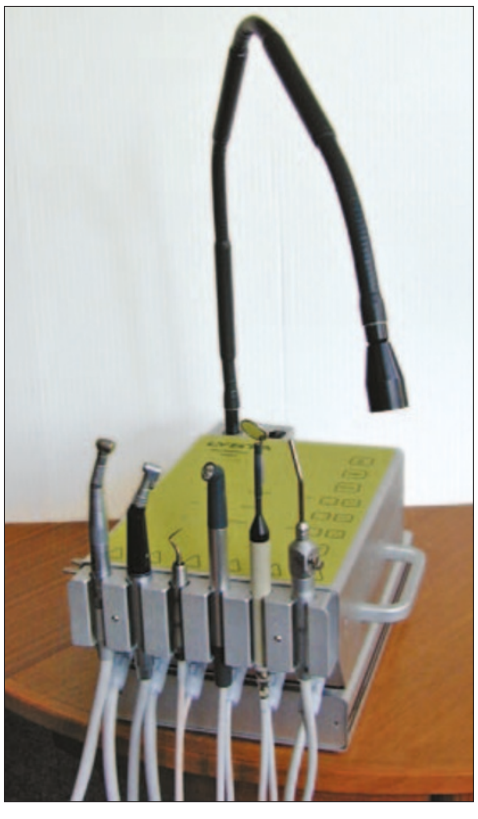
board and all instruments can be operated by a control panel or by cordless foot control. For further information contact01844213399 or email lystauk@aol.com.

\section{Specialist brushes for perio patients}

Perio patients may benefit from TePe's range of products, which are perfectly suited for cleaning every patient's interdental spaces. The range includes eight interdental brushes ranging from fine (xxxx-fine, $0.4 \mathrm{~mm}$ pink) to the $x$-large

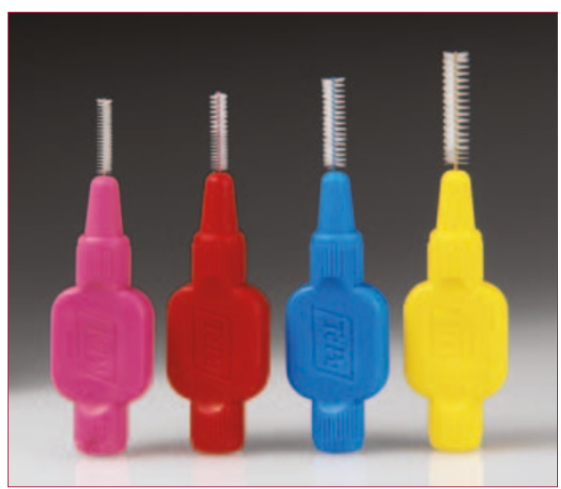
grey $(1.3 \mathrm{~mm})$. Colour coded for easy identification, some of the range is now available from selected retailers. The range includes TePe Soft Tape and plastic and wooden interdental sticks, and other specialist brushes. The TePe Compact Tuft is perfect for cleaning along the gum line, around partially erupted teeth and in furcation sites. The TePe Interspace is available in three different textures and is easily manipulated around restorations and difficult to reach areas. 


\section{Controlling cross infection}

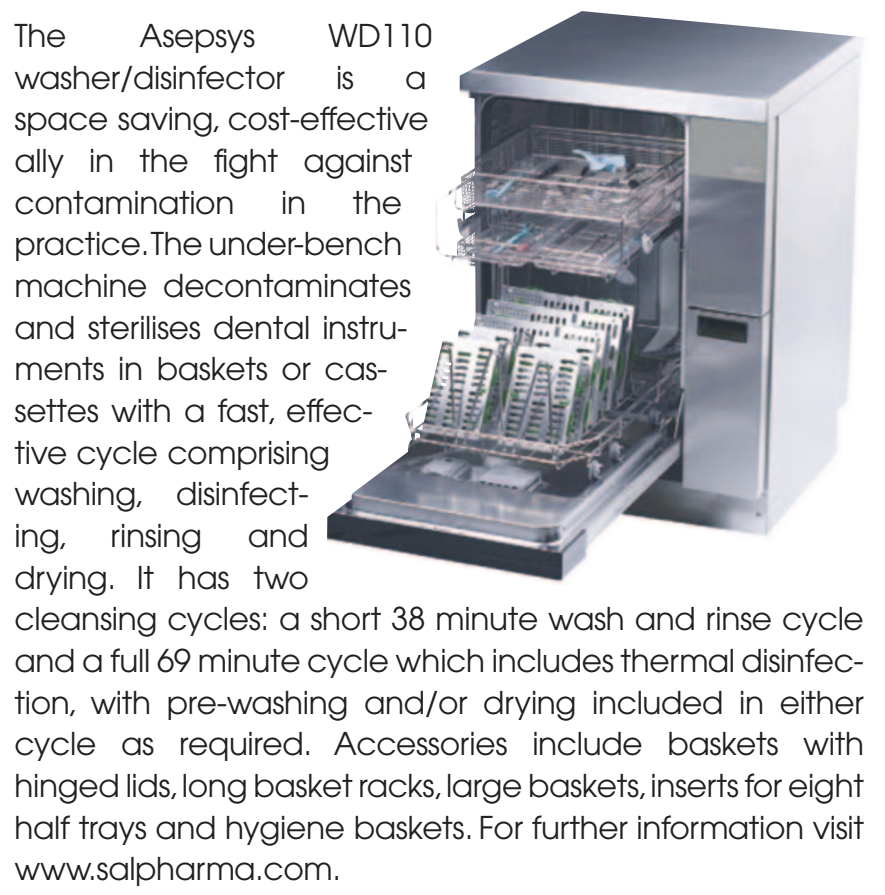

\section{New pre-sterilised examination kit}

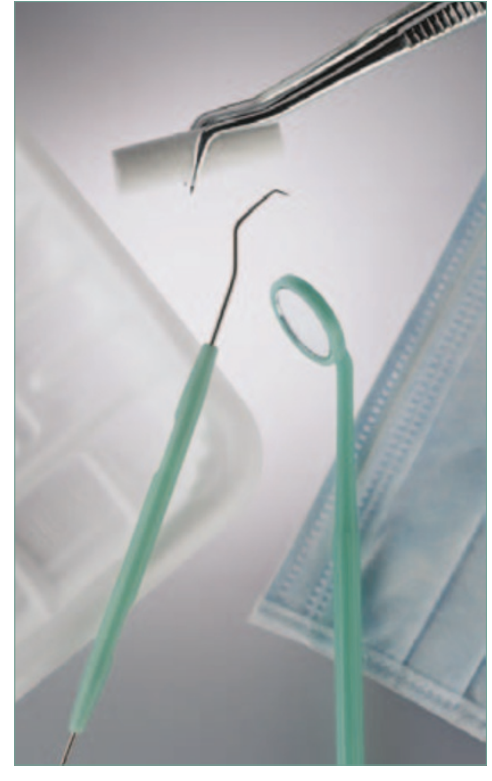

in compact boxes of 50. For further information contact KerrHawe on 01733892292.

\section{Association contacts}

\section{BRITISH ASSOCIATION OF DENTAL NURSES}

Pam Swain (Chief Executive), PO Box 4, Room 200, Hillhouse International Business Centre, Thornton-Cleveleys, FY5 4QD Tel: $\quad 01253338360$ Email: admin@badn.org.uk Website: www.badn.org.uk

\section{BRITISH ASSOCIATION OF DENTAL THERAPISTS}

Jane Lewis (Secretary), c/o 92 Mayfield Drive, Caversham, Reading, Berkshire, RG4 5JT

Tel: $\quad 01189482651$

Email: badt@freeuk.com

Website: www.badt.org.uk

\section{BRITISH DENTAL} HYGIENISTS' ASSOCIATION

Ann Craddock (Administrator),

Mobbs Miller House, Ardington Rd,

Northampton, NN1 5LP

Tel: $\quad 08702430752$

Email: enquiries@bdha.org.uk

Website: www.bdha.org.uk

\section{BRITISH DENTAL PRACTICE MANAGERS' ASSOCIATION \\ Bridget Crump (Chairman), \\ Osprey House, Primett Road, \\ Stevenage, Herts \\ SG1 3EE \\ Tel: $\quad 08708400381$ \\ Email: info@bdpma.org.uk \\ Website: www.bdpma.org.uk}

\section{DENTAL TECHNICIANS' ASSOCIATION}

Sue Adams (Registrar),

PO Box 6520,

Northampton, NN3 9ZX

Tel: $\quad 08702430753$

Email: sueadams@dta-uk.org

Website: http://www.dta-uk.org

\section{ORTHODONTIC NATIONAL} GROUP OF DENTAL NURSES

Helen Grice-Roberts (Chairman),

9 Barge Close, Aldershot,

Hants, GU11 2PB

Tel: $\quad 01252341990$

Email: Debra.claire@btinternet.com

Website: www.orthodontic-ong.co.uk

\section{DENTAL LABORATORIES} ASSOCIATION

Michael Egerton (Chairman), 44-46 Wollaton Road,

Beeston, Nottingham

NG9 2NR

Tel: $\quad 08709914525$

Email: enquiries@dla.org.uk

Website: www.dla.org.uk

\section{ORTHODONTIC}

TECHNICIANS' ASSOCIATION

Paul Mallett (Secretary),

The Maxillofacial Laboratory,

Royal Lancaster Infirmary,

Ashton Road,

Lancaster, Lancs

LA1 4RP

Website: www.orthota.co.uk

\section{BRITISH DENTAL}

RECEPTIONISTS' ASSOCIATION

Gemma Bowen,

24 Farnworth Grove,

Castle Bromwich,

Birmingham

B36 9JA

Tel: $\quad 08700801924$

Email: gemma@bdra.co.uk

Website: www.bdra.co.uk 